\title{
Open-field behavior in mice: Genetic analysis of repeated measures'
}

\section{J. P. HEGMAN V, University of lowa, Iowa City, lowa, and J. C. DeFRIES, University of Colorado, Boulder, Colo.}

Open-field activity and defecation scores on each of two successive days were obtained on $6.37 \mathrm{~F} 2$ and $8+1 \mathrm{~F} 3 \mathrm{SS}_{\mathrm{S}}$ and subjected to genetic analysis. Heritabilities of second-day activity and defecation scores were found to be lower than those of first day scores. Genetic and phenotypic correlations among the single-day behaviors were also estimated. From these results it was concluded that activity on Days 1 and 2 and defecation on Day 2 are influenced by many of the same genes and that high open-field activity on Dais 1 and ? are both indices of low emotional reactivity.

Individual differences in a character have both genetic and environmental bases. Variance due to heritable differences may be ascribed to various causes: Additive genetic variance $\left(V_{A}\right)$ is due to the average effects of genes in a population. whereas dominance and epistasis give rise to non-additive genetic variance $\left(\mathrm{V}_{\mathrm{N}_{A}}\right)$. The total or phenotypic variance $\left(\mathrm{V}_{\mathrm{P}}\right)$ of a character may be partitioned into genetic and environmental components as follows: $V_{P}=V_{A}+V_{N A}+V_{E}$, where $V_{E}$ is the environmental variance. The heritability $\left(h^{2}\right)$ of a character in a population. defined as $h^{2}=V_{A} / V_{P}$. is a parameter which has both descriptive and predictive properties (Falconer, 1960) and which is thus useful in the genetic analysis of behavioral characters (see DeFries, 1967).

Heritability estimates for repeated measurements of behavioral characters have been found to increase (Broadhurst \& Jinks, 1961). decrease (Broadhurst \& Jinks. 1966) and fluctuate randomly (Fuller \& Thompson, 1960) as a function of repeated testing. Therefore. the pattern of change in heritability associated with successive measurement appears to be variable. However. $h^{2}$ is population and character specific: thus. the effects of test experience on the heritability of a character may depend upon the population and trait under investigation.

The observed correlation between two characters also has both genetic and environmental causes. The genetic correlation between two characters may be due to pleiotropy (manifold effects of genes) or to linkage (the effects of which should be relatively temporary) and may serve as an index of the extent to which two measures are influenced by the same genes (Falconer, 1960). Thus. high genetic correlations among repeated behavioral measures should indicate that performance on successive tests is controlled by the same genetic system.

The primary objective of the present study was to conduct a genetic analysis of open-field activity and defecation scores on each of two successive days in mice. The heritabilities of single-day scores and the genetic and phenotypic correlations among them will be reported. A detailed genetic analysis of total scores is presented elsewhere (DeFries \& Hegmann. in press).

\section{METHOD}

The 330 male and 307 female F 2 Ss observed were descendants of an original cross of two inbred strains of mice (BALB/cJ and $(57 \mathrm{BL} / 6 \mathrm{~J})$ which differ widely in open-field behavior. Matings among randomly chosen $F 2$ Ss yielded 128 litters comprising 407 male and 434 female F3 Ss. All F 2 and F3 Ss were tested for $3 \mathrm{~min}$ on each of to successive days at $40 \pm 5$ days of age in a brightly lighted open field $(36 \times 36$ in.) constructed of white, painted Plexiglas. Two sets of five light sources were beamed through holes and red filters to photoconductive cells on the opposite side. effectively dividing the floor of the field into 36 squares $(6 \times 6$ in.), and the number of light beams broken was automatically recorded on counters. Activity scores and number of fecal boluses dropped were recorded daily and subjected to square root transformations. Due to low mean defecation scores, 0.5 was added to these raw scores prior to transformation.

Heritabilities of single-day measures were estimated from the regression of scores of F3 Ss on their F2 mid-parental values. Due to variable litter size, regressions were weighted according to the number of animals in a litter. Standard errors were calculated according to the method presented by Falconer (1960). Genetic correlations among all single-day behaviors were estimated from the cross-covariance of scores of F3 Ss and their F 2 mid-parental values. Ss. behavioral testing. and the validity of the methods employed for estimating the genetic parameters are discussed in more detail elsewhere (DeFries \& Hegmann, in press).

\section{Heritability}

\section{RESULTS AND DISCUSSION}

Estimates of $\mathrm{h}^{2}$ for open-field activity scores on Days 1 and 2 were $0.28 \pm 0.09$ and $0.09 \pm 0.07$. respectively. Corresponding estimates for defecation scores on Days 1 and 2 were $0.14 \pm 0.06$ and $0.07 \pm 0.06$. $V_{A}$ associated with activity on Days 1 and 2 was 2.86 and 1.24 , respectively. while $V_{E}+V_{N A}$ was 7.35 and 12.55. However, with regard to defecation, $V_{A}$ associated with Day 1 and Day 2 scores was 0.05 and 0.025 , respectively, and $V_{E}+V_{X A}$ was 0.31 and 0.34 . Therefore, the decrease in $\mathrm{h}^{2}$ of activity scores on successive days was due to both a decrease in $V_{A}$ and an increase in $V_{E}+V_{X_{A}}$. Whereas the decrease in $h^{2}$ of defecation scores was due almost entirely to a change in $V_{t}$.

This pattern of a lower $h^{2}$ for second day measures is in agreement with the results of Broadhurst \& Jinks $(1960)$ in their genetic analysis of the same behaviors in rats. In addition. a somewhat similar pattern of change in components of variance accounted for their results. Although the $h^{2}$ estimates reported by Broadhurst \& Jinks (1966) were approximately three times as large as those of the present study. it is interesting to note that the pattern of change in $h^{2}$ associated with repeated measurement was similar when analogous behaviors were observed in different species.

Correlations

Genetic and phenotypic correlations among the single-day behavioral scores are presented in Table 1. The genetic correlation between activity on Days 1 and 2 is large and

Table 1

Genetic Correlations \pm S.E. (above diagonal) and Phenotypic Correlations (below diagonal) Among Single-Day. Open-Field Behavioral Scores

\begin{tabular}{ccccc}
\hline & $\begin{array}{c}\text { Day 1 } \\
\text { Activity }\end{array}$ & $\begin{array}{c}\text { Day 2 } \\
\text { Activity }\end{array}$ & $\begin{array}{c}\text { Day 1 } \\
\text { Defecation }\end{array}$ & $\begin{array}{c}\text { Day 2 } \\
\text { Defecation }\end{array}$ \\
\hline $\begin{array}{c}\text { Day 1 } \\
\text { Activity }\end{array}$ & & $.94 \pm .04$ & $-.51 \pm .19$ & $-.89 \pm .07$ \\
$\begin{array}{c}\text { Day 2 } \\
\text { Activity }\end{array}$ & .63 & & $-.10 \pm .41$ & $-.76 \pm .24$
\end{tabular}

Day 1

Defecation

$-.3+\quad-.23$

$.20 \pm+1$

Day ?

Defecation
$-.47$

32 
positive and those between defecation on Day 2 and both single-day activity scores are large and negative, indicating that these three measures are influenced by many of the same genes. In contrast, genetic correlations of these three measures with defecation on Day 1 are erther intermediate or low; thus, defecation on Day 1 appears to be influenced by a somewhat different genetic system.

The phenotypic correlation (pooled within sex and generation, $\mathbf{N}=1,478$ ) between activity on Days 1 and 2 is moderately large and positive, whereas that between defecation on Days 1 and 2 is smaller. Each of the four phenotypic correlations involving a single-day activity score and a single-day defecation measure is negative and intermediate.

The above results suggest that open-field activity on Days 1 and 2 are similar behaviors. In contrast, Whimbey \& Denenberg (1967) have recently concluded that open-field activity by rats on Day 1 was measuring something quite different from activity on subsequent test days. In their study, 96 Wistar rats from an experiment employing a $2^{4}$ factorial arrangement of treatments were tested in an open field on four successive days prior to and one day following measurement on an extensive battery of tests. A mean score was obtained for each of the 16 experimental groups on each of the measures and then intercorrelated. Day 1 activity scores correlated positively with all defecation scores and loaded positively on an "emotionality factor," whereas subsequent activity scores correlated negatively with all defecation scores and loaded negatively on this factor. From these results, Whimbey \& Denenberg (1967) suggest that high activity scores on Day 1 are indicative of high emotionality, but that high activity scores on subsequent days indicate low emotionality.
The results of the present study, however, demonstrate a negative association between activity and defecation on both Days 1 and 2. In fact, genetic correlations of Day 1 activity with both single-day defecation scores are negative and larger than those among activity on Day 2 and these defecation measures. These results suggest that high open-field activity on Day 1 may also serve as an index of low emotional reactivity. The discrepancy between the results of the present study and those of Whimbey \& Denenberg (1967) may be due in part to the considerable difference in methods and Ss employed.

\section{REFERENCES}

BROADHURST, P. L., \& JINKS, J. L. Biometrical genetics and behavior: Analysis of published data. Psychological Bulletin, 1961, 58, 337-362.

BROADHURST, P, L, \& JINKS, J. L. Stability and change in the inheritance of behaviour in rats: A further analysis of statistics from a diallel cross. Proceedings of the Royal Society, B., 1966, 165, 450-472.

DeFRIES, J. C. Quantitative genetics and behavior: Overview and perspective. In J. Hirsch (Ed.), Behavior-genetic analysis. New York: McGraw-Hill, Inc., 1967. Pp. 322-339.

DeFRIES, J. C., \& HEGMANN, J. P. Genetic analysis of open-field behavior. In G. Lindzey and D. D. Thiessen (Eds.), Contributions to behavior-genetic analysis: The mouse as a prototype (in press).

FALCONER, D. S. Introduction to quantitative genetics. New York: The Ronald Press Company, 1960.

FULLER, J. L., \& THOMPSON, W. R. Behavior genetics. New York: John Wiley \& Sons, Inc., 1960.

WHIMBEY, A. E., \& DENENBERG, V. H. Two independent behavioral dimensions in open-field performance. Journal of Comparative and Physiological Psychology, 1967, 63, 500-504. NOTE

1. This study was part of a thesis submitted by the senior author in partial fulfillment of the requirements for the degree of Doctor of Philosophy at the University of Illinois. Supported in part by NIH Grants GM-12486 and GM-15679. We thank E. A. Thomas for his assistance. 